\title{
Research on the $\mathrm{O} 20$ Mode and Corresponding Influences on the Online and Offline Internet Marketing
}

\author{
Yajuan Sun \\ Xijing University, \\ Xi'an,Shaanxi,710123 China
}

\begin{abstract}
In this paper, we conduct research on the O2O mode and corresponding influence on the online and offline Internet marketing. Precision marketing is on the basis of fully understanding of consumer information, according to its characteristics and primary preferences targeted to carry out the one-to-one marketing. Mobile Internet users are mostly fixed which can be the new network technology in-depth insight into consumer interest and demand, and to establish for each specific customer database. Based on the analysis of customer data, then according to the characteristics of the different customers and the preference information such as the precision marketing, at the same time which can also according to customer's feedback information targeted adjustment of products and the marketing, in order to better meet the needs of customers. Our research combines the O2O concepts and the technique to propose the novel marketing paradigm which is of great importance.
\end{abstract}

Keywords- O2O Mode, Online and Offline, Internet Marketing, Corresponding Influences.

\section{Introduction}

The development of the Internet is a process from closed to open, started in 1998 before and after the China's Internet, after the access to the king, content is king, the application is king after three stages of development, various applications such as the video, search, community has become the Internet enterprise standard, across the multiple application of the Internet enterprises constantly emerging, Internet companies the homogeneity degree of deepening, the Internet enterprise in order to grab the user's first entry, to provide users with rich application products, with the degree of user access to the Internet, the user demand for Internet applications become more and more tend to be more diversified and personalized. Network marketing after entering China from many scholars on it are analyzed, and pointed out that when the stage the problems and put forward the corresponding countermeasure, but different times have different opinions, there are different problems, and some problems have been repeatedly mentioned, network marketing development in China can be divided into early and late.

At present, the primary challenges for the Internet marketing could be summarized as follows. (1) Network competition consciousness is not strong, the understanding of the network marketing is not clear. Both in business and personal network marketing is a lack of understanding, we do not have the right to realize the network marketing enterprise development space and the network marketing has become a developing trend, will produce a great push to the development of enterprises. (2) Lack of customer relationship management mechanism. Network marketing for the center with product, do not take the customer as the center, lack of customer relationship management mechanism, centered on products for enterprises and individuals will have negative influence, to the enterprise is difficult to form the understanding of customers' information and credit, and hard to improve the quality of the service. (3) China's network marketing has the characteristics of localization, and the Internet as a means of transmission of network marketing, the characteristics of the China's Internet will certainly affect the network marketing, if we don't know China the paradox of the Internet began to do network marketing, and copy some way in the United States that is clearly not the right thing to do [1-3]. 
The Internet has the unconsciously penetrated into our lives, and as we can on the cable offline business $\mathrm{O} 2 \mathrm{O}$ mode also got great development. As the BAT in the $\mathrm{O} 2 \mathrm{O}$ layout, $\mathrm{O} 2 \mathrm{O}$ also once again become the focus of industry development. We see not only the Internet, mobile Internet enterprises in developing $\mathrm{O} 2 \mathrm{O}$ business, the traditional industry such as catering, tourism, retail, housekeeping, wedding, maternal and infant industries are $\mathrm{O} 2 \mathrm{O}$ business layout, digging a new customer. $\mathrm{O} 2 \mathrm{O}$, so to speak that has become involved in many industries a new nuggets point. $\mathrm{O} 2 \mathrm{O}$ is the purpose of the user from line to line down consumption, in the development of China's Internet industry and the $\mathrm{O} 2 \mathrm{O}$ business started very early development. Before conducting in-depth analysis on the $\mathrm{O} 2 \mathrm{O}$, we firstly demonstrate the general flowchart of the modern Internet based marketing in figure one.

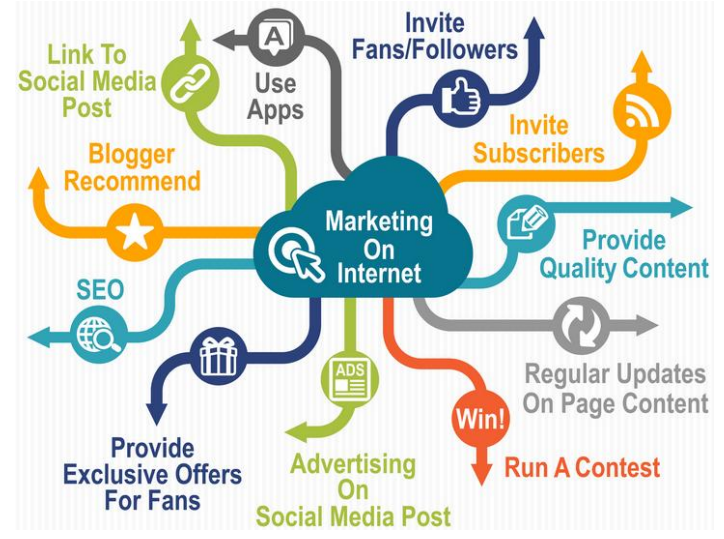

Figure 1. The General Flowchart of the Modern Internet based Marketing

In this paper, we conduct research on the $\mathrm{O} 2 \mathrm{O}$ mode and corresponding influence on the online and offline Internet marketing. With the development of China's Internet, it gradually began to share brand advertising budget. This share is not really seems to steal money, in fact it is a kind of momentum by flooding. For the world's largest Internet market in China, financial enterprises to learn to use network marketing become necessary in nowadays environment to survive. In the following later sections, we will analyze the corresponding issues in detail.

\section{The Proposed Methodology}

The Principles of Enterprise Marketing. Our country enterprise is more practical, mostly in the marketing, pay more attention to "pin" in sales, and to "camp" namely brand construction investment is not big, in the management of the enterprise internal marketing personnel, more emphasis on the individual ability, the team not to notice, this also and stakeholders as the lack of marketing idea of keeping pace with the times. It is different from administrative monopoly as economy monopoly in a particular stage is conducive to the development of productivity. Economy monopoly implementation process is actually a competition in the market efficiency and industrial competitiveness. The current our country some enterprise and industry cluster has advantages in the market that have to economic monopoly implementation conditions. Through to the enterprise and industry cluster has economic monopoly implementation capability, namely, the core competitiveness, creativity, profitability, three aspects of comparative analysis that found in these three respects each has its advantages. Under this background, we summarize the features of the modern enterprise marketing as follows [4-5].

- Marketing service idea lag behind. In the enterprise, with the strengthening of system reform, the enterprise put forward the higher attention to the service, service system has been perfect, though, in the enterprise marketing attaches great importance to the service concept has been the people, but the enterprise service construction started relatively late, there are many of the problems in the marketing process.

- The management pattern backwardness. Traditional service not have a systemic management mode, the management system can be effectively controlled, in terms of service also does not have unity, so the enterprise overall management is chaotic. In the face of the same customer 
demand, because of the enterprise did not set rules and regulations, different business people often according to their wishes to provide different services to our customers.

- The imperfection of the marketing management system. Enterprise in the marketing service management process, there is no set up perfect management system as many business people to provide services according to their own idea, in the process of service management problem not timely summary, once appear problem didn't formulate preventive measures in advance.

From the marketing point of view, professional must first customer value analysis. Companies to provide value must match the buyer's value of the seller. The advantage of the enterprise on supplier value chain through specialization must provide the customers with special interests. Enterprise can through customer value analysis to understand the relative advantages and disadvantages of the value chain and then select the professional field. In the customer value analysis, the main properties, the enterprises should first identify customer value through market research, understand customer needs and expectations of product features and benefits, and then according to the interests of the customer to product characteristics and evaluation, judge the importance of the different attributes, finally, the enterprise can sorting and classification, the importance of product, and comparing with competitors, identifying their advantages and disadvantages from the comparison [5].

The Internet Marketing Techniques. From the core perspective of the "marketing", the network marketing can be defined as: network marketing is a component of the enterprises overall marketing strategy, is to achieve overall management goal of enterprise, with the Internet as the basic means, to create online business environment of a variety of activities. This definition shows that the essence of network marketing and traditional marketing is the same, all is in order to understand customer needs and meet them; At the same time, it is no longer a promotion so simple but through the entire process of marketing, from market research before product launch, to product the design and manufacturing process, to marketing communications, to after-sales service network marketing runs through whole process of marketing. The figure 2 illustrates the corresponding concepts [6-7].

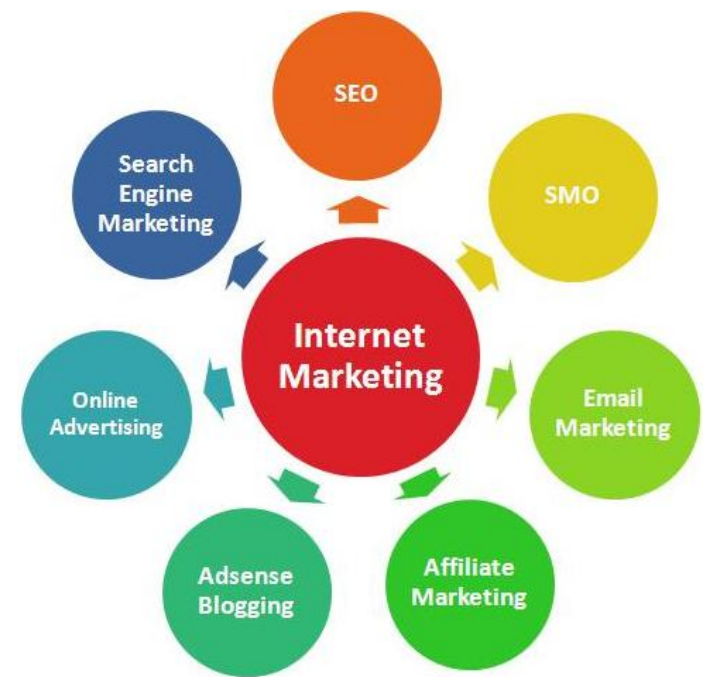

Figure 2. The Primary Components of the Internet Marketing

Currently, the Internet marketing is following trend of mobilization which can be reflected from the listed aspects. (1) Based on the geographic location of the service marketing. The carrying of the mobile phones and smartphones generally have positioning system, make the enterprise can according to user's location to carry out targeted services marketing. (2) Customized advertising. One of the strengths of the mobile Internet marketing can be for different end users production of different forms and contents of the advertisements. The illicit close sex of the mobile phone users and uniqueness, determines the terminal of the received feedback information is true and reliable, it will provide the support for the advertising custom. Through cooperation 
with the mobile web portal that can effective implementation of this strategy. (3) More real and humanized marketing experience. Such marketing way not only for mobile phone users save time and energy, also can excavate potential customers for the enterprise and expand market share to contribute.

Compared with the traditional media, new media's biggest characteristics of the age of the Internet are interactive. Under the environment of the new media marketing model, the consumers can not only passive to accept messages, select information can also be targeted, and with every interaction between businesses that make the marketing more effectiveness and pertinence, greatly improve the efficiency and quality of marketing. Internet era of new media can be text, images, audio, video and other way to convey information, to enrich marketing content, expand the marketing capacity, flexible form, the purpose of making marketing more attractive and creativity, to meet the personalized needs.

The 020 Mode. Generation and development of the $\mathrm{O} 2 \mathrm{O}$ is closely related to the Internet and the mobile devices. China O2O market began to rapid development, online, at stage to mobile browser, social media and APPS as the main form, on line, main entrance to the commercial application of QR code, mobile payment and the near field communication as main means [8].

Online and offline is one of the core concept of $\mathrm{O} 2 \mathrm{O}$ delivered to the customer service and product consistency. But if the enterprise internal, different departments and different people have different judgment criteria, that is below the consistency of the product is not guaranteed, of course also cannot guarantee the consistency of primary online and offline. In short, the integration of $\mathrm{O} 2 \mathrm{O}$ is with the development of e-commerce, a large number of entities enterprises begin to attach importance to the inevitable result of the online channel. Some current the $\mathrm{O} 2 \mathrm{O}$ website, most also only stay in online promotion and marketing level, not go deep into the core operation process. But as the electronic commerce of the bubble burst, to treat the electronic commerce enterprise more sober understanding, there will be more and more enterprises, trying to make more deep $\mathrm{O} 2 \mathrm{O}$ integration, online that will eventually merge into the battlefield.

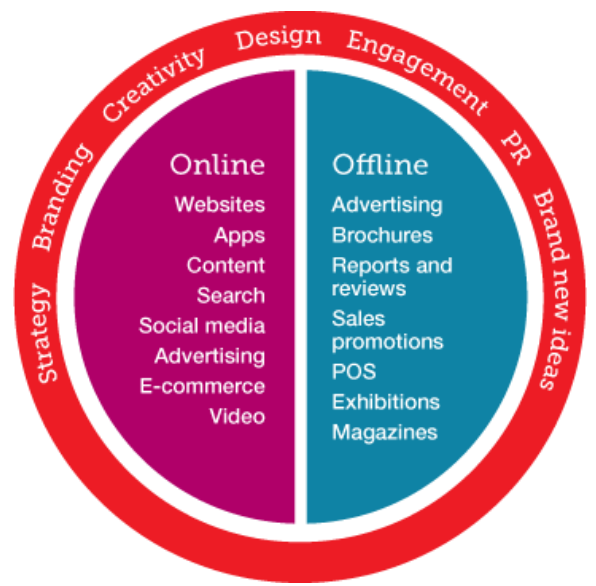

Figure 3. The Characteristics of the O2O Mode

The Precision Marketing. The development of modern science and technology make tremendous changes have taken place in people's life style, people are paying more attention to the self, stress individual character and the consumer demand is more and more diversification. Companies face to capture and meet the challenge of dispersed customers need.

The media analysis thinks, interactive, accuracy and positioning of the three trends connect with each other, promote each other. In Internet search technology, social media management, customer orientation technology, the cloud computing, such as the online advertising will evolution towards the direction of the people-oriented, emphasis on enterprise to interact with people and trust, and to meet the personalized needs. Structured management of the user interest classification decision this easy exchange that can provide customers with end-to-end integrated marketing solutions, integration, at present this easy exchange has been extended audience insight, creative development and testing, integration of media 
planning, advertising directional delivery and the general optimization, customer relationship management and integrated marketing reports six product lines, different combinations bring different marketing experience for the customer.

Precision marketing mainly includes the target object is the main feature of selectivity, namely as accurately as possible to select target consumers, pertinence of communication; The effectiveness of communication strategy, namely the strategy as effective as possible that can touch the audience; Communication behavior of the economy; The communication with the target audience of high return on investment, reduce waste; Communicate results can be measured, is the result of communication and the cost can be measured as much as possible to avoid the "feeling" influences.

\section{Conclusion}

In this paper, we conduct research on the $\mathrm{O} 2 \mathrm{O}$ mode and corresponding influence on the online and offline Internet marketing. As a kind of new marketing and communication, network marketing has yet to be perfected and developed. Believe that with the development of network technology and the popularity of Internet, network marketing in China's development will also be very fast, but still there may be some problems need to pay attention to and solved, by means of network marketing in nearly a decade in China, the problems existing in the development process, lists several common problems, through the analysis of these problems can clear the direction and focus to solve the problem, to provide some references for the development of network marketing in the Chinese market, enterprises can also according to their respective situation to make adjustment of the network marketing plan.

\section{References}

[1] Bianchi, Constanza, and Shane Mathews. "Internet marketing and export market growth: an empirical study in Chile." Journal of Business Research (2014).

[2] Bowie, David, Alexandros Paraskevas, and Anastasia Mariussen. "Technology-Driven Online Marketing Performance Measurement: Lessons from Affiliate Marketing." International Journal of Online Marketing (IJOM) 4.4 (2014): 1-16.

[3] Doostar, Mohammad, and Mohammad Hossein Mohammadi. "Studying and prioritising the effective elements of internet advertising on e-marketing." International Journal of Services and Operations Management 18.1 (2014): 57-73.

[4] Hsieh, Jung-Kuei, Yi-Ching Hsieh, and Yu-Chien Tang. "Exploring the disseminating behaviors of eWOM marketing: persuasion in online video." Electronic Commerce Research 12.2 (2012): 201-224.

[5] Laroche, Michel, and Seong-Yeon Park. "Recent advances in globalization, culture and marketing strategy: Introduction to the special issue." Journal of Business Research 66.8 (2013): 955-957.

[6] Motameni, Reza, and Richard Nordstrom. "Correlating the Social Media Functionalities to Marketing Goals and Strategies." Journal of Marketing Management 2 (2014): 3-4.

[7] Miranda, Francisco Javier, Sergio Rubio, and Antonio Chamorro. "The Web as a Marketing Tool in the Spanish Foodservice Industry: Evaluating the Websites of Spain's Top Restaurants." Journal of Foodservice Business Research 18.2 (2015): 146-162.

[8] Montgomery, Kathryn C., et al. "The digital food marketing landscape: challenges for researchers." Advances in Communication Research to Reduce Childhood Obesity. Springer New York, 2013. 221-242. 